OPEN ACCESS

Edited by:

Uichin Lee,

College of Engineering, KAIST,

South Korea

Reviewed by:

Seungjaeq Shin,

Mississippi State University,

United States

Isaac Vaghefi,

Binghamton University, United States

*Correspondence:

Mi Jung Rho

romy1018@naver.com; romy1018@catholic.ac.kr

Specialty section:

This article was submitted to

Digital Public Health,

a section of the journal

Frontiers in Public Health

Received: 27 May 2020

Accepted: 29 July 2020

Published: 11 September 2020

Citation:

Park J, Jeong J-E, Park Sy and Rho MJ (2020) Development of the Smartphone Addiction Risk Rating Score for a Smartphone Addiction

Management Application

Front. Public Health 8:485.

doi: 10.3389/fpubh.2020.00485

\section{Development of the Smartphone Addiction Risk Rating Score for a Smartphone Addiction Management Application}

\author{
Jihwan Park ${ }^{1}$, Jo-Eun Jeong ${ }^{2}$, Seo yeon Park ${ }^{3}$ and Mi Jung Rho ${ }^{4 *}$ \\ ${ }^{1}$ Department of Biomedicine and Health Sciences, College of Medicine, The Catholic University of Korea, Seoul, \\ South Korea, ${ }^{2}$ Department of Psychiatry, College of Medicine, Daejeon St. Mary's Hospital, The Catholic University of Korea, \\ Daejeon, South Korea, ${ }^{3}$ Computer Science and Engineering, Chung-Ang University, Seoul, South Korea, ${ }^{4}$ Catholic Cancer \\ Research Institute, The Catholic University of Korea, Seoul, South Korea
}

Smartphone usage characteristics are useful for identification of the risk factors for smartphone addiction. Risk rating scores can be developed based on smartphone usage characteristics. This study aimed to investigate the smartphone addiction risk rating (SARR) score using smartphone usage characteristics. We evaluated 593 smartphone users using online surveys conducted between January 2 and January 31, 2019. We identified 102 smartphone users who were addicted to smartphones and 491 normal users based on the Korean Smartphone Addiction Proneness Scale for Adults. A multivariate logistic regression analysis was used to identify significant risk factors for smartphone addiction. The SARR score was calculated using a nomogram based on the significant risk factors. Weekend average usage time, habitual smartphone behavior, addictive smartphone behavior, social usage, and process usage were the significant risk factors associated with smartphone addiction. Furthermore, we developed the SARR score based on these factors. The SARR score ranged between 0 and 221 points, with the cut-off being 116.5 points. We developed a smartphone addiction management application using the SARR score. The SARR score provided insights for the development of monitoring, prevention, and prompt intervention services for smartphone addiction.

Keywords: smartphone addiction, smartphone addiction risk rating score, Korean smartphone addiction proneness scale for adults (S-scale), nomogram, smartphone addiction management application

\section{INTRODUCTION}

Smartphones are multipurpose devices in modern life with various functions and benefits. Smartphones have diverse applications (apps) to provide user-friendly interfaces for information, communication, connection, education, and entertainment $(1,2)$ that promote intensive or habitual smartphone usage. Smartphones are usually used unintentionally. Unconscious smartphone users underestimate their usage time by $40 \%$ and they actually use smartphones $15 \%$ more (3). Smartphone addiction could have a negative impact on the academic performance and psychological, physical, financial, and social aspects of life (4-6). Smartphone addiction has led to uncontrolled usage of smartphones, withdrawal symptoms, and obstacles in daily life. 
Smartphone addiction is an important issue regarding social behavior and mental health. It is a social problem that needs to be tackled, and various studies are underway for explore this issue. To solve this problem, identification of the risk factors that cause smartphone addiction is necessary. Therefore, previous studies have attempted to identify these risk factors and solve the negative consequences of smartphone addiction (7-9). It is important to identify the negative factors of smartphone addiction, especially based on the smartphone usage characteristics.

Smartphone usage characteristics have known risk factors. Some studies have used smartphone usage characteristics to determine smartphone addiction. Smartphone addiction is associated with smartphone usage characteristics (2, 10). Haug et al. (2) found that the duration of smartphone use on a typical day was associated with smartphone addiction in young people. Therefore, some studies developed an app to collect smartphone usage data, such as total usage duration, to assess smartphone addiction $(11,12)$. Lin et al. (11) proposed that non-use frequency and non-use duration significantly predicted smartphone addiction from the mobile app. Previous related apps have focused on one-dimensional usage, such as the amount of smartphone use $(2,13)$. Venkatesh et al. (14) found that longer duration of smartphone use, high frequency of use, shorter time until the first use of the smartphone in the morning, and social networking service (SNS) use were significantly related to smartphone addiction. Recently, studies have focused on the type and frequency of smartphone use $(10,15,16)$. Some researches focused on hourly pattern and app preferences of smartphones (3).

Thus, smartphone usage characteristics are significant factors for monitoring, preventing, and intervening smartphone addiction. In terms of mental health, approaches using smartphone use characteristics are worth researching to overcome smartphone addiction, and various approaches are needed. There are many opportunities to develop behavioral intervention services for smartphone addiction. Based on these factors, development of the smartphone addiction risk rating score (SARR score) is required for the monitoring, prevention, and prompt intervention of smartphone addiction.

The smartphone addiction scale (SAS) is based on smartphone usage characteristics and the Korean self-diagnostic program for Internet addiction (K-scale) (17). The SAS consisted of the following six factors: daily-life disturbance, positive anticipation, withdrawal, cyberspace-oriented relationship, overuse, and tolerance. The SAS is an excellent scale for smartphone addiction; however, there are limitations regarding development of various intervention services by applying this scale to our app. Development of various scales for the prediction and prevention of smartphone addiction is necessary. This study indicated that the development of a risk rating score, which can predict smartphone risk by reflecting only the smartphone usage characteristics, is necessary. We required an approach to monitor and prevent smartphone addiction with the smartphones usage characteristics that we can easily collect. Here, we attempted to develop the SARR score based on smartphone usage characteristics and an app that could manage smartphone addiction using the SARR score.

\section{MATERIALS AND METHODS}

\section{Sample}

We recruited 593 smartphone users from online surveys conducted between January 2 and January 31, 2019. All participants completed an anonymous web-based survey conducted by a polling company. The polling company delivered an email, including the online survey link and informed consent link, to the online panel. After consenting to the online survey, panel could participate in web-based questionnaires. The inclusion criteria were as follows: participants who were smartphone users and aged between 20 and 59 years. Respondents with the same answer, meaningless answer responders, and logical error responders were excluded from the study. In addition, we regarded the responses of those who responded faster than the minimum expected time as meaningless responses; therefore, we excluded them.

We identified smartphone users that were addicted to the smartphones and normal users based on the Korean Smartphone Addiction Proneness Scale for Adults (S-scale) (18). The participants' data were de-identified. Written informed consent was not required for this study in accordance with national guidelines and local legislation.

\section{Measures and Procedure}

There were nine variables in this study: one dependent variable and eight independent variables.

First, we used the S-Scale as a dependent variable (18). The SScale consisted of 15 items scored with a four-point Likert scale (from 1: "not at all" to 4: "always"). The S-Scale was composed of four main categories: daily-life disturbance (five items), virtual world orientation (two items), withdrawal (four items), and tolerance (four items). The total scores were categorized into three subgroups (0-39: none; 40-43: at-risk group; and over 44: risk group). Smartphone users with S-Scale scores above 44 were evaluated as the high-risk group for smartphone addiction. The low-risk group for smartphone addiction included both a non-risk group and an at-risk group.

Second, we used the eight independent variables related to smartphone use and sleeping time (Supplementary Table 1). The smartphone use-related factors were weekday smartphone use time, weekend smartphone use time, weekly (7 days) frequency of use, process usage, social usage, habitual usage, and addictive usage.

The duration of smartphone use on a typical day is associated with the smartphone addiction in young people (2). Frequent smartphone use and frequency trends have relationships with the smartphone addiction $(10,19)$. Thus, we used the weekday smartphone use time, weekend smartphone use time, and weekly frequency of use as the meaningful factors in evaluating smartphone addiction.

There are two smartphone use behaviors: habitual and addictive smartphone behavior (20). We considered these two smartphone use behaviors as the smartphone use types. In this 
research, we perceived that smartphone addiction is a negative outcome of the smartphone use; behavior was considered as the process before the negative outcome of smartphone addiction. Thus, we focused on the habitual and addictive smartphone behavior as a risk factor for smartphone addiction.

In this study, habitual smartphone behavior meant repeated smartphone use without self-instruction or conscious thinking (20-22). The habitual smartphone behavior subscale consisted of six items scored with a five-point Likert scale (from 1: "never" to 5: “always") (20).

Addictive smartphone behavior meant intensive smartphone use behavior (20). The addictive smartphone behavior subscale consisted of 26 items scored with a five-point Likert scale (from 1: "never" to 5: "always") (20). In previous research, addictive smartphone behavior subscale consisted of a 10-point Likert scale. However, we used the addictive smartphone behavior subscale as a five-point Likert scale to save the respondents response time. Both the habitual and addictive smartphone behavior questionnaires measured the perception of smartphone usage patterns and characteristics.

In this study, process usage meant smartphone use for cultural and ritual processes, to receive gratification from the pleasurable experience of media content, and to realize during consumption rather than the content alone. Swanson proposed that there are two dimensions of gratifications: process and content gratification. Process gratification is derived from the pleasurable experience of media content and is realized during consumption $(23,24)$. Content gratifications are derived from learning information from media content and subsequently, using it in practical affairs. The process usage subscale consisted of seven items scored with a five-point Likert scale (from 1: "never" to 5: "always") (20).

In this study, social usage meant smartphone use for social reasons. The social usage subscale consisted of five items scored with a five-point Likert scale (from 1: "never" to 5: "always").

Finally, we used sleeping time as an independent variable. High smartphone use has a relationship with late bedtime (25). Sleeping disturbances occur across many mental health conditions (26). Sleep period markers have a relationship with the severity of depressive symptoms (27). Sleep periods can be detected by observing on/off phone screens in heavy phone users (28). Thus, we assumed that sleeping time was an important factor to be considered as an independent variable to evaluate smartphone addiction.

Based on existing literature, eight variables were selected by four smartphone addiction field professionals and experts (two psychiatrists, one medical information expert, and one data scientist). After evaluating internal consistency reliability and construct validity of four variables, we used the following items of variables: addictive smartphone behavior $(n=11)$, habitual smartphone behavior $(n=5)$, social usage $(n=5)$, and process usage $(n=3)$ (Supplementary Table 2).

\section{Statistical Analysis}

The 593 smartphone users were analyzed using the $\mathrm{R}$ package (version 4_3.5.0). A multivariate logistic regression analysis was used to identify significant smartphone addiction risk factors for smartphone addiction. After the multivariate logistic regression analysis, we used the logistic regression-based nomogram to calculate the SARR score. The logistic regression-based nomogram created a risk score based on the derived logistic regression equation. The sum of each derived score was the final SARR score.

Nomogram is a visual tool that could predict the risk factors affecting the disease without complicated calculations. Even non-statistical experts can use nomograms to make decisions (29). A nomogram is created from a mathematical equation, which is typically complicated. Specially, the logistic regression-based nomogram has the benefit of providing output probability calculations based on fast and simple graphical methods. Each variable's weight is clear and expresses its relative importance (30).

We used the $\mathrm{R}$ Regression Modeling Strategies package (version 5.1-3) ( $\mathrm{R}$ language; $\mathrm{R}$ version 3.5.0; 2018-04-23) to develop the SARR score from a logistic regression-based nomogram, using significant smartphone addiction risk factors. The logistic regression-based nomograms have long been used in diverse diseases $(31,32)$.

We randomly divided the original data set into training and test data set. Data splitting is an approach for cross-validation (29). We matched six training datasets to four test datasets. Figure 1 shows the research process.

\section{RESULTS}

As shown in Table 1, 51.3\% of the respondents were male. The respondents' ages ranged between 20 and 59 years. Of the total respondents, $55.6 \%$ were married or living with a partner. Approximately $71.3 \%$ of the respondents had occupations, such as office workers, administrative positions, service industry positions, professional technicians, freelancers, and production employees. A total of $61.9 \%$ of the respondents received over $\$ 3,584.23$ as their monthly income. In addition, $66.4 \%$ of the respondents lived in the capital area, and $80.9 \%$ of the respondents had Android phones. Finally, $17.2 \%$ of the participants were in the high-risk group for smartphone addiction based on the S-scale. There were 102 users in the high-risk group and 491 users in the low-risk group.

\section{Risk Factors Predicting Smartphone Addiction}

Four independent variables were evaluated by internal consistency reliability using Cronbach's alpha (Supplementary Table 2). The values for all constructs ranged between 0.645 and 0.928 (0.928 for addictive smartphone behavior; 0.895 for habitual smartphone behavior; 0.819 for social usage; and 0.645 for process usage). The values for three constructs were $>0.7$ (33). The value of process usage was 0.645. Consequently, the Cronbach's alpha for all constructs were reliable. To test the construct validity, we performed a principal component analysis with varimax rotation. The cross-loadings were lower than the corresponding factor loadings. Four factors emerged with no-cross construct 


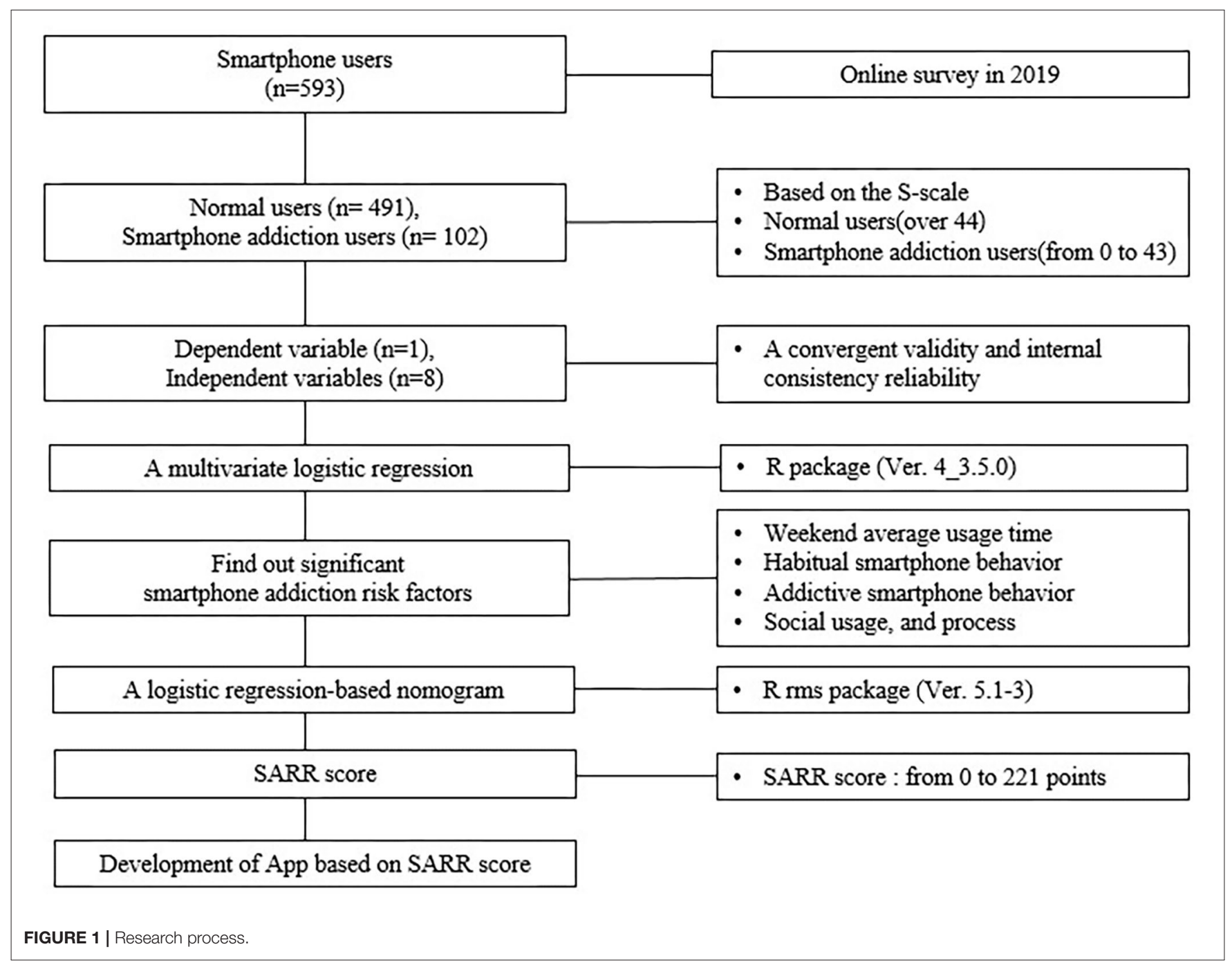

loadings above 0.50 . The pattern of loadings and cross-loadings supported the discriminant validity and internal consistency. The analysis also demonstrated a convergent validity with factor loadings exceeding 0.50 for each construct. The results confirmed the existence of four factors with eigenvalues $>1.0$ that accounted for $63.222 \%$ of the total variance. In addition, communality ranged between 0.496 and 0.735 , with all items achieving the 0.50 threshold (Supplementary Table 2). These results confirmed that the four constructs were distinct unidimensional scales.

Table 2 shows the classification table of the multivariate logistic regression model. All variables included in the logistic regression model were free of multicollinearity. One of the measure for model performance in general linear model, Nagelkerke's $R^{2}$ was 0.668 . Accuracy of model was 91.4.

Table 3 shows the results of the multivariate logistic regression analysis. Smartphone weekend average usage times (odds ratio $[\mathrm{OR}]=1.002$ ) were significant predictors of smartphone addiction. In addition, the process usage, social usage, habitable usage, and addictive usage of smartphones were significant factors that predicted the smartphone addiction $(\mathrm{OR}=1.160$, $0.786,1.267$, and 1.162 , respectively).

\section{The SARR Score Based on the Logistic Regression-Based Nomogram}

We developed the SARR score based on the logistic regressionbased nomogram as depicted in Figure 1. The total prediction rate was $91 \%$, which was considered reasonably accurate. The specificity was $96 \%$ and the sensitivity was $66 \%$. Thus, this study accepted these results.

Figure 2 shows the nomogram of SARR score. The SARR score nomogram consisted of a series of measures corresponding to each variable in the equation. It could freeze the values of point variables to check the relationship between the following nonfixed variables: smartphone weekend average usage time, process usage, habitual smartphone behavior, addictive smartphone behavior, and social usage. We could obtain point values of a variable by placing a straight line against a point value of the scale, a value at a location that intersects the scale of that variable. A 
TABLE 1 | Demographic characteristics of the respondents.

\begin{tabular}{|c|c|c|c|}
\hline \multicolumn{2}{|l|}{ Variables } & \multirow{2}{*}{$\begin{array}{c}\text { Frequency } \\
304\end{array}$} & \multirow{2}{*}{$\begin{array}{c}\text { Percentage } \\
51.3\end{array}$} \\
\hline Sex & Male & & \\
\hline & Female & 289 & 48.7 \\
\hline \multirow[t]{4}{*}{ Age } & 20-29 years & 132 & 22.3 \\
\hline & $30-39$ years & 139 & 23.4 \\
\hline & 40-49 years & 169 & 28.5 \\
\hline & 50-59 years & 153 & 25.8 \\
\hline \multirow[t]{2}{*}{ Marital status } & Single ${ }^{a}$ & 263 & 44.4 \\
\hline & Couple $^{a}$ & 330 & 55.6 \\
\hline \multirow[t]{3}{*}{ Occupation } & Office worker, etc. ${ }^{b}$ & 423 & 71.3 \\
\hline & Student & 82 & 13.8 \\
\hline & $\begin{array}{l}\text { Housewife, unemployed } \\
\text { and other }\end{array}$ & 88 & 14.8 \\
\hline \multirow[t]{4}{*}{ Monthly income } & Under $\$ 1,792.11$ & 47 & 7.9 \\
\hline & $\$ 1,792.11-\$ 3,584.23$ & 179 & 30.2 \\
\hline & $\$ 3,584.23-\$ 5,376.34$ & 219 & 36.9 \\
\hline & Over $\$ 5,376.34$ & 148 & 25.0 \\
\hline \multirow[t]{2}{*}{ Residential area } & $\begin{array}{l}\text { Capital area (including } \\
\text { Seoul) }\end{array}$ & 394 & 66.4 \\
\hline & Non-capital area & 199 & 33.6 \\
\hline \multirow[t]{2}{*}{ Device type } & Android & 480 & 80.9 \\
\hline & Apple iOS & 113 & 19.1 \\
\hline \multirow[t]{3}{*}{ Group } & $\begin{array}{l}\text { Low-risk group for } \\
\text { smartphone addiction }\end{array}$ & 491 & 82.8 \\
\hline & $\begin{array}{l}\text { High-risk group for } \\
\text { smartphone addiction }\end{array}$ & 102 & 17.2 \\
\hline & Total & 593 & 100.0 \\
\hline
\end{tabular}

a Single: never married, divorced, separated, or widowed; Couple: married or living with a partner. ${ }^{b}$ Office worker, etc.: office worker, administrative position, service industry position, professional technician, freelancer, and production employee. The exchange rate for Korean won to the US dollar is $1,116.00$ won (buy and sell base rate in January 31, 2019).

predicted value intersects the total points, which is summation of point values of these variables.

The total risk rating score was calculated as the sum of the values for each variable (Table 4). The SARR score ranged between 0 and 221 points. The cutoff of the SARR score was 116.5 points. In the receiver operating characteristic curve, the cutoff value represented the portion where the sensitivity and specificity of the graphs overlapped (sensitivity: 0.823 and specificity: 0.831 ) (Supplementary Figures 1, 2).

Figure 3 shows the calibration of SARR score. The calibration was assessed by categorizing the smartphone users by their SARR score. The calibration was assessed based on the plot of predicted probabilities between the nomogram and actual probabilities (29). The calibration of smartphone addiction illustrated how its predictions were compared with the actual outcomes of the 593 smartphone users (34). The $\mathrm{x}$-axis is the predicted value calculated using the SARR score, and the y-axis is the actual smartphone addiction probability of the smartphone users (35). The best predictions corresponded to the $45^{\circ}$ line. Points estimated below the $45^{\circ}$ line represented over-prediction, and
TABLE 2 | Classification table.

\begin{tabular}{|c|c|c|c|c|}
\hline & \multicolumn{3}{|c|}{ Prediction value } & \multirow[b]{2}{*}{ Accuracy } \\
\hline & $\begin{array}{c}\text { Normal } \\
\text { users }\end{array}$ & $\begin{array}{l}\text { Smartphone users } \\
\text { addicted to the } \\
\text { smartphones }\end{array}$ & Total & \\
\hline Normal users & 475 & 16 & 491 & 96.7 \\
\hline $\begin{array}{l}\text { Smartphone users } \\
\text { addicted to the } \\
\text { smartphones }\end{array}$ & 35 & 67 & 102 & 65.7 \\
\hline Total & 510 & 83 & 593 & 91.4 \\
\hline
\end{tabular}

those above the $45^{\circ}$ line represented under-prediction (36). The SARR score prediction line was close to $45^{\circ}$ and the results were appropriate.

\section{Smartphone Addiction Management App Based on the SARR Score}

We developed the smartphone addiction management app to manage smartphone addiction using the SARR score. Figure 4 shows the app process based on the SARR score. Survey response values of a user obtained from questionnaires through the app related to weekend average usage time, habitual smartphone behavior, addictive smartphone behavior, social usage, and process usage are presented in Figure 4. These response values are inputs of the formula of the SARR score as presented in the center of Figure 4. This formula calculates the SARR score using the user's questionnaire response values as the input values. The SARR score was visualized on the result screen of the app. An intervention service can be provided to manage the smartphone addiction according to the derived SARR score.

\section{DISCUSSION}

We identified five relevant factors among smartphone usage characteristics and developed the SARR score based on meaningful factors. Based on the results of this study, the following conclusions were derived:

First, smartphone weekend average usage time, process usage, social usage, habitable usage, and addictive usage of smartphones were relevant variables in smartphone addiction. In particular, smartphone weekend average usage time was the only important factor in terms of smartphone addiction among these factors.

The number of hours spent on smartphone use explains the smartphone addiction (37). However, weekly frequency of use and weekday smartphone use time had no relationship with smartphone addiction. Most people keep their smartphones on, use them frequently, and rely on them. On average, people check their smartphone 46 times per day (38). Thus, normal smartphone users also use smartphones frequently 
TABLE 3 | Risk factors predicting smartphone addiction.

\begin{tabular}{|c|c|c|c|c|}
\hline Parameter & Estimate & SE & $p$-value & OR $95 \% \mathrm{Cl}$ \\
\hline Intercept & -17.137 & 2.215 & 0.000 & \\
\hline Smartphone use weekday time & -0.001 & 0.001 & 0.449 & $0.999(0.997-1.001)$ \\
\hline Smartphone weekend averages usage time & 0.002 & 0.001 & $0.040^{\star \star}$ & $1.002(1.000-1.004)$ \\
\hline Weekly frequency to use & 0.000 & 0.001 & 0.635 & $1.000(0.998-1.001)$ \\
\hline Sleeping time & -0.003 & 0.002 & 0.126 & $0.997(0.993-1.001)$ \\
\hline Process usage & 0.149 & 0.057 & $0.009^{\star \star}$ & $1.160(1.038-1.297)$ \\
\hline Social usage & -0.241 & 0.063 & $0.000^{\star \star \star}$ & $0.786(0.695-0.889)$ \\
\hline Habitual smartphone behavior & 0.236 & 0.060 & $0.000^{\star \star \star}$ & $1.267(1.126-1.425)$ \\
\hline Addictive smartphone behavior & 0.150 & 0.017 & $0.000^{\star \star \star}$ & $1.162(1.123-1.203)$ \\
\hline
\end{tabular}

$S E$, standard error; OR, odds ratio; $\mathrm{Cl}$, confidence interval.

${ }^{* \star} p<0.01 ;{ }^{* \star *} p<0.001$; Time unit: minute.

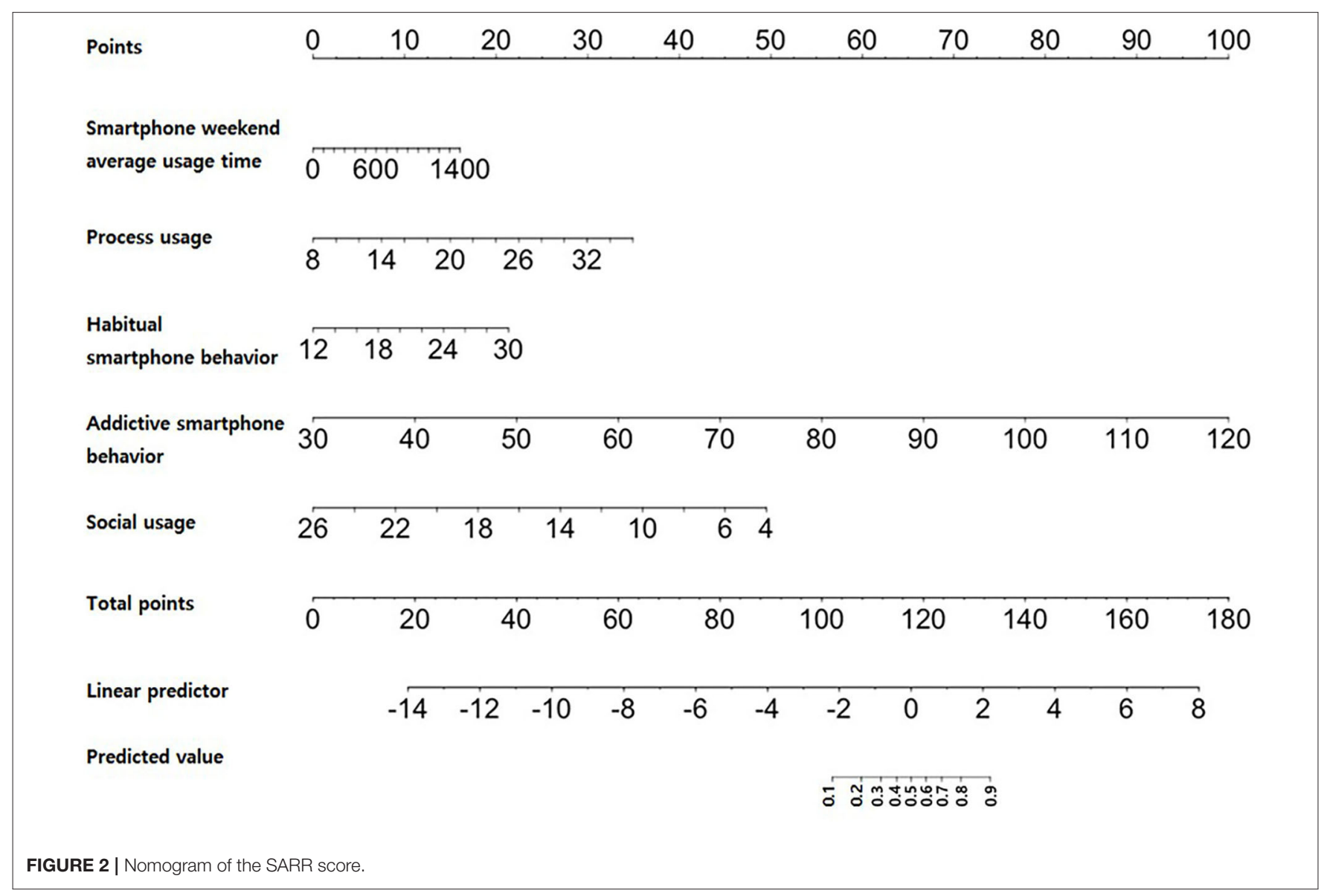

on the weekend and have a high frequency of smartphone use. Frequent smartphone use is associated with smartphone addiction $(10,11,19)$. Our results differ from those of previous studies regarding frequent smartphone use been associated with smartphone addiction. Recently, studies have focused on the type of smartphone use and frequency of smartphone use (15). Thus, a separate approach is needed for studying smartphone use time for smartphone addiction in detail with regard to the following factors: smartphone weekday usage time and weekend usage time.
We also found that process usage and social usage influenced smartphone addiction. Currently, many people have relationships with other people through their smartphones and the cyber world (39). Social networking is a personal and relevant smartphone function and has an association with smartphone addiction (2). The SNS use was a stronger predictor of the smartphone addiction than the game use (40). Social reasons also lead to the highest levels of addiction to the Internet (41). Smartphones have diverse functions of providing a userfriendly interface for information, communication, education, 
TABLE 4 | Smartphone addiction risk rating score.

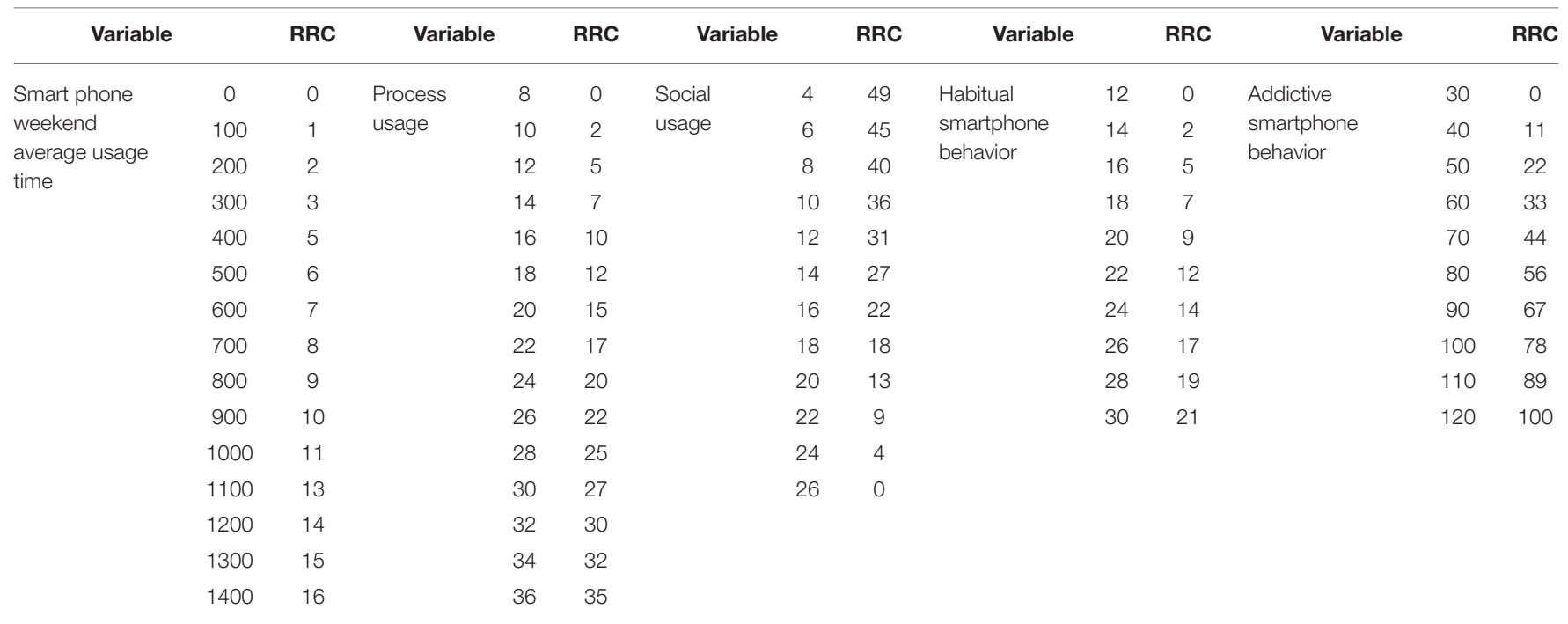

Time unit, minute; $R R C$, risk rating score.

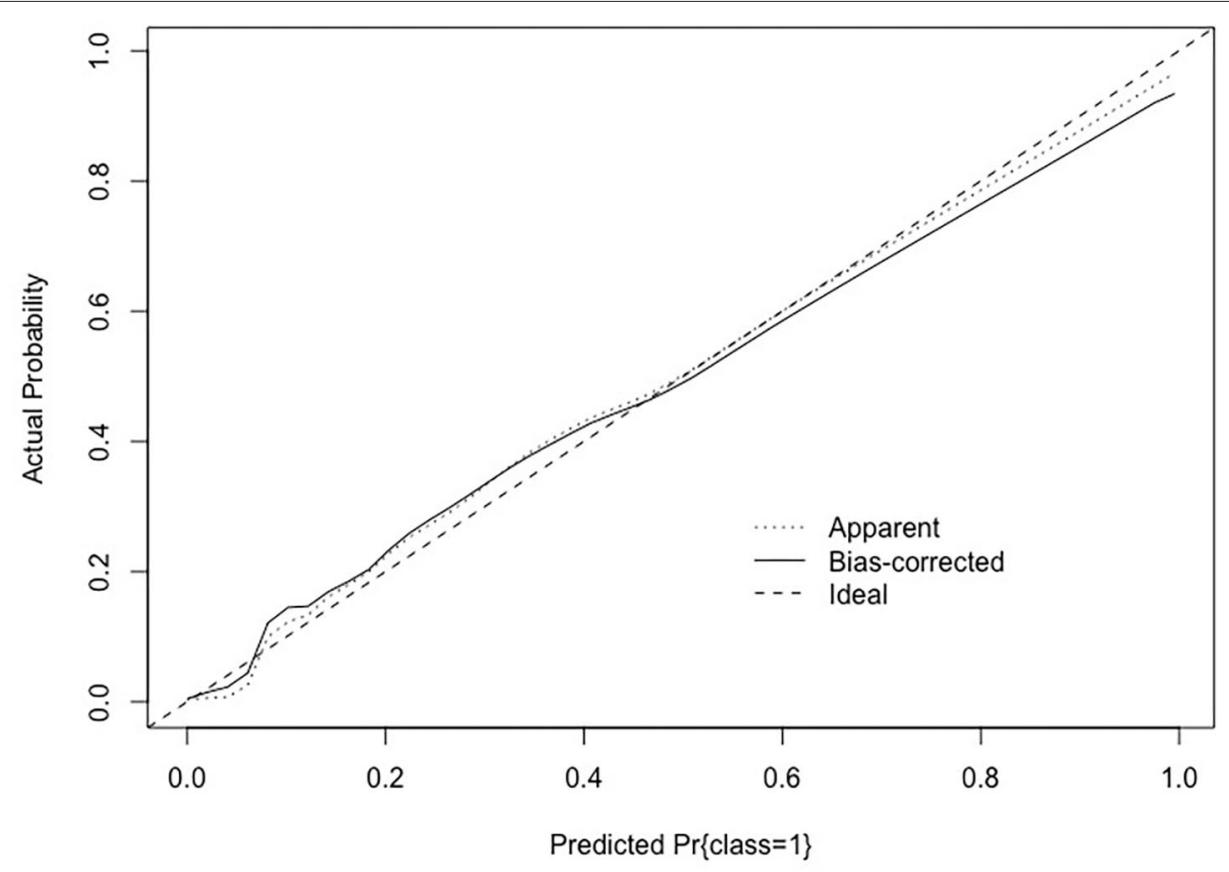

FIGURE 3 | Calibration of the SARR score.

and entertainment. Smartphone users receive gratification from the pleasurable experience of smartphone content, and the gratification is realized during consumption. Smartphones are specialized in using mobile messengers and SNS, it can be used for social interaction and relationships anytime, anywhere (42). This smartphone usage characteristic may lead to smartphone addiction.

In addition, we focused on two concepts of smartphone usage characteristics: habitual and addictive smartphone behavior. This study also found that habitual and addictive smartphone behaviors make smartphone use more pervasive. Oulasvirta et al. proposed that habits make smartphone use more pervasive (22). Habitual behavior is an automatic response to internal and external cues (43). Van Deursen et al. also proposed the concept of habitual and addictive smartphone behavior (20). Habitual smartphone behavior influences addictive smartphone behavior and smartphone addiction. However, habitual smartphone behavior is 

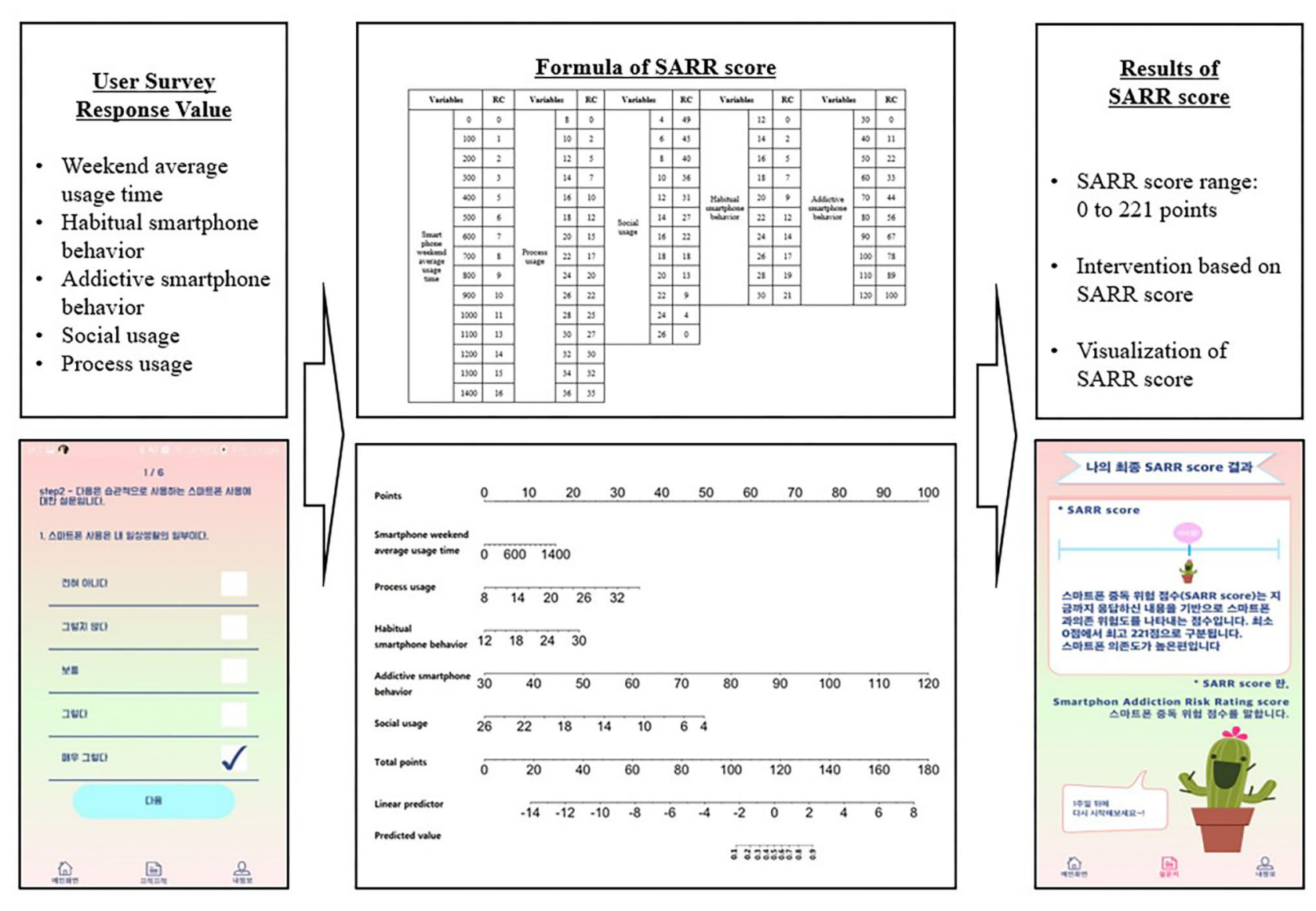

FIGURE 4 | App process based on the SARR score.

not addictive smartphone behavior and smartphone addiction. Accordingly, separate concepts of smartphone use are needed.

Second, we developed the SARR score based on five relevant factors as follows: smartphone weekend average usage time, process usage, social usage, habitable usage, and addictive usage. The SARR score ranged between 0 and 221 points. If we collected the data for these five factors, we could express the risk score visually in intervention service. The risk score could be used to develop smartphone addiction monitoring, prevention, and prompt intervention. We are developing smartphone addiction monitoring, prevention, and prompt intervention services using the SARR score. We hope that these services will help smartphone users to control their smartphone use by themselves.

Third, we found that sleeping time was not an important factor for smartphone addiction. Previous researchers have proposed that feeling good is greatly influenced by receiving enough sleep (44). Sleep plays a significant role in mental health. Many studies have focused on sleep as a behavioral marker in mental health and smartphone addiction $(27,45-48)$. We found no relationship between sleeping time and smartphone addiction. A previous study reported that the sleep duration on weekends and midpoint of sleep on weekdays and weekends did not predict the smartphone addiction (25). In addition, previous researches proposed that sleep quality mediated the relationship between problematic smartphone use and health symptoms, such as body dysfunction (49). Thus, sleep time can be a significant variable in intervention of smartphone addiction, but more research is needed.

Fourth, we focused on a logistic regression-based nomogram to develop the risk score in smartphone addiction. As explained earlier, the logistic regression-based nomogram has the benefit of providing output probability calculations based on fast and simple graphical methods. In addition, each variable's weight is clear and expresses its relative importance (30). Although the logistic regression-based nomograms have long been used in diverse diseases $(31,32,50,51)$, fewer attempts have been made to use nomograms in mental health studies. Our attempt represents a meaningful approach.

Finally, although there is the SAS based on the K-scale (17), we still developed the SARR score. The SAS consisted of the following six factors: daily-life disturbance, positive anticipation, withdrawal, cyberspace-oriented relationship, overuse, and tolerance. The SAS has good psychometric qualities. The SAS is a suitable scale for judging smartphone addiction; however, there are limitations regarding development of various intervention services by applying this scale to the apps. This is 
because SAS does not specifically enquire regarding smartphone usage characteristics. Thus, we developed the SARR score to further develop a smartphone addiction management app. We had to evaluate smartphone addiction risk status of the users periodically for app service. It is not reasonable to ask psychological questions to smartphone users every time for the intervention of smartphone addiction. App users are cumbersome and have a psychological burden. We judged that it is necessary to develop the SARR score that can predict smartphone risk rate by reflecting only the smartphones usage characteristics, which can be collected easily. The SARR score will be useful for all services through smartphone intervention apps.

Although significant results were obtained from this study, it had some limitations. First, we used smartphone use data from a self-reported questionnaire. Future research should assess real smartphone use by collecting data from mobile devices. Second, we only focused on the smartphone usage characteristics. Future research should focus on other psychiatric symptoms, such as depression and anxiety (4). Third, there is no previous related risk score based on only smartphone usage characteristics for smartphone addiction. Hence, we could not compare our results with other risk models. Fourth, although there are variables related to smartphone use, various literatures do not exist yet. A lot of in-depth research is needed. Fifth, we used the term "smartphone addiction" in this study. Various related terms, such as problematic smartphone use, excessive smartphone use, smartphone dependence, and smartphone addiction, are used (52-55). There is no consensus within the academic community or representation in clinical manuals that a particular term is recognized. We recognized the controversy of this issue. Hence, if agreement on terms is reached; it would be desirable to interpret this study in terms of the term agreed upon in the future. Sixth, in the case of sleep time, various measurements are possible, such as App sensing data or Pittsburgh sleep quality index (56). In this study, sleep time was measured only by one item in the self-reported questionnaire; hence, it is necessary to collect and analyze the sleep time by other methods. Seventh, the SARR score is intended to monitor the smartphone addiction risk rate and status, rather than be a tool for judging smartphone addiction. In the future, for the psychiatrists to use it in determining smartphone addiction, further research will be needed based on actual smartphone usage. Finally, we used the S-Scale scored with a four-point Likert scale to identify 102 smartphone users that were addicted to the smartphones and 491 normal users. In case of a four-point Likert scale, there was no medium point in the measurement of the items. Using a four-point scale is problematic and could have potentially distorted the results. However, to use the SScale cut-off, the five-point scale of the original S-Scale must be used. When the scale is adjusted to five points, the cutoff is arbitrarily changed. Future research should use the five-point SScale to identify the smartphone addiction group with a new cutoff value. This can be evaluated as a different topic from this study.

\section{CONCLUSIONS}

This study developed the SARR score that can predict smartphone risk by reflecting only the smartphone usage characteristics. It was developed for smartphone addiction monitoring, prevention, and providing prompt and timely intervention services. We further developed the smartphone addiction management app using the SARR score. The developed app may be efficiently used for managing actual smartphone use. In addition, the SARR score could be extended to other mental health issues and contexts.

\section{DATA AVAILABILITY STATEMENT}

The raw data supporting the conclusions of this article will be made available by the authors, without undue reservation.

\section{ETHICS STATEMENT}

The studies involving human participants were reviewed and approved by Institutional Review Board of Catholic University (IRB number: MC18QNSI0101). Written informed consent for participation was not required for this study in accordance with the national legislation and the institutional requirements.

\section{AUTHOR CONTRIBUTIONS}

The study was designed by JP and MR. Data collection was performed by MR. Statistical analyses have been conducted by JP and MR, whereas J-EJ advised on some of the clinical approaches. The manuscript has been written by MR. In detail, JP drafted the complete method and statistical analysis section, whereas J-EJ and MR together drafted the introduction. JP, J-EJ, and MR drafted the discussion, which was then clinically revised by J-EJ. JP, J-EJ, and MR independently checked all statistical results. SP developed the app to manage smartphone addiction. The final version has been approved by all authors.

\section{FUNDING}

This work was supported by the National Research Foundation of Korea (NRF) grant funded by the Korea government (MSIT) (NRF-2018R1C1B6007750).

\section{ACKNOWLEDGMENTS}

All authors are grateful for Jinhyun Han's efforts in designing the app.

\section{SUPPLEMENTARY MATERIAL}

The Supplementary Material for this article can be found online at: https://www.frontiersin.org/articles/10.3389/fpubh. 2020.00485/full\#supplementary-material 


\section{REFERENCES}

1. Okazaki S, Hirose M. Does gender affect media choice in travel information search? On the use of mobile Internet. Tour Manag. (2009) 30:794804. doi: 10.1016/j.tourman.2008.12.012

2. Haug S, Castro RP, Kwon M, Filler A, Kowatsch T, Schaub MP. Smartphone use and smartphone addiction among young people in Switzerland. J Behav Addict. (2015) 4:299-307. doi: 10.1556/2006.4.2015.037

3. Lee H, Ahn H, Nguyen TG, Choi S-W, Kim DJ. Comparing the self-report and measured smartphone usage of college students: a pilot study. Psychiatry Investig. (2017) 14:198-204. doi: 10.4306/pi.2017.14.2.198

4. Rho MJ, Park J, Na E, Jeong J-E, Kim JK, Kim D-J, et al. Types of problematic smartphone use based on psychiatric symptoms. Psychiatry Res. (2019) 275:46-52. doi: 10.1016/j.psychres.2019.02.071

5. Shen $\mathrm{L}, \mathrm{Su}$ A. Intervention of smartphone addiction. In: Multifaceted Approach to Digital Addiction and Its Treatment. IGI Global (2019). p. 207-28. doi: 10.4018/978-1-5225-8449-0.ch010

6. Samaha M, Hawi NS. Relationships among smartphone addiction, stress, academic performance, and satisfaction with life. Comput Human Behav. (2016) 57:321-5. doi: 10.1016/j.chb.2015.12.045

7. Barnes SJ, Pressey AD, Scornavacca E. Mobile ubiquity: understanding the relationship between cognitive absorption, smartphone addiction and social network services. Comput Human Behav. (2019) 90:246-58. doi: 10.1016/j.chb.2018.09.013

8. Kim S-G, Park J, Kim H-T, Pan Z, Lee Y, McIntyre RS. The relationship between smartphone addiction and symptoms of depression, anxiety, and attention-deficit/hyperactivity in South Korean adolescents. Ann Gen Psychiatry. (2019) 18:1. doi: 10.1186/s12991-019-0224-8

9. Herrero J, Torres A, Vivas P, Urueña A. Smartphone addiction and social support: a three-year longitudinal study. Psychosoc Interv. (2019) 28:1118. doi: 10.5093/pi2019a6

10. Lin Y-H, Lin Y-C, Lee Y-H, Lin P-H, Lin S-H, Chang L-R, et al. Time distortion associated with smartphone addiction: Identifying smartphone addiction via a mobile application (App). J Psychiatr Res. (2015) 65:13945. doi: 10.1016/j.jpsychires.2015.04.003

11. Lin $Y$, Lin $Y$, Lin S, Lee $Y$, Lin P, Chiang C, et al. To use or not to use? Compulsive behavior and its role in smartphone addiction. Transl Psychiat. (2017) 7:e1030. doi: 10.1038/tp.2017.1

12. Lee $\mathrm{H}$, Ahn $\mathrm{H}$, Choi $\mathrm{S}$, Choi W. The SAMS: smartphone addiction management system and verification. J Med Sys. (2014) 38:1. doi: 10.1007/s10916-013-0001-1

13. Augner C, Hacker GW. Associations between problematic mobile phone use and psychological parameters in young adults. Int J Public Health. (2012) 57:437-41. doi: 10.1007/s00038-011-0234-z

14. Venkatesh E, Al Jemal MY, Al Samani AS. Smart phone usage and addiction among dental students in Saudi Arabia: a cross sectional study. Int J Adolesc Med Health. (2017) 31:1-7. doi: 10.1515/ijamh-2016-0133

15. Bae S-M. The relationship between the type of smartphone use and smartphone dependence of Korean adolescents: National survey study. Child Youth Serv Rev. (2017) 81:207-11. doi: 10.1016/j.childyouth.2017. 08.012

16. Tossell C, Kortum P, Shepard C, Rahmati A, Zhong L. Exploring smartphone addiction: Insights from long-term telemetric behavioral measures. Int J Interactive Mobile Technol. (2015) 9:37-43. doi: 10.3991/ijim.v9i 2.4300

17. Kwon M, Lee J-Y, Won W-Y, Park J-W, Min J-A, Hahn C, et al. Development and validation of a smartphone addiction scale (SAS). PLoSone. (2013) 8:e56936. doi: 10.1371/journal.pone.0056936

18. Shin K, Kim D, Jung Y. Development of Korean Smart Phone Addiction Proneness Scale for Youth and Adults. Seoul: Korean National Information Society Agency (2011).

19. Liu C-H, Lin S-H, Pan Y-C, Lin Y-H. Smartphone gaming and frequent use pattern associated with smartphone addiction. Medicine (Baltimore). (2016) 95:e4068. doi: 10.1097/MD.0000000000004068

20. Van Deursen AJ, Bolle CL, Hegner SM, Kommers PA. Modeling habitual and addictive smartphone behavior: the role of smartphone usage types, emotional intelligence, social stress, self-regulation, age, and gender. Comput Human Behav. (2015) 45:411-20. doi: 10.1016/j.chb.2014.12.039
21. LaRose R, Eastin MS. A social cognitive theory of Internet uses and gratifications: Toward a new model of media attendance. J Broadcast Electron Media. (2004) 48:358-77. doi: 10.1207/s15506878jobem4803_2

22. Oulasvirta A, Rattenbury T, Ma L, Raita E. Habits make smartphone use more pervasive. Pers Ubiquit Comput. (2012) 16:105-14. doi: 10.1007/s00779-011-0412-2

23. Song I, Larose R, Eastin MS, Lin CA. Internet gratifications and internet addiction: on the uses and abuses of new media. Cyberpsychol Behav. (2004) 7:384-94. doi: 10.1089/cpb.2004.7.384

24. Swanson DL. Understanding audiences: continuing contributions of gratifications research. Poetics. (1992) 21:30528. doi: 10.1016/0304-422X(92)90011-Q

25. Randler C, Wolfgang L, Matt K, Demirhan E, Horzum MB, Beşoluk SJ. Smartphone addiction proneness in relation to sleep and morningnesseveningness in German adolescents. J Behav Addict. (2016) 5:46573. doi: $10.1556 / 2006.5 .2016 .056$

26. Sivertsen B, Krokstad S, Øverland S, Mykletun A. The epidemiology of insomnia: Associations with physical and mental health.: The HUNT-2 study. J Psychosom Res. (2009) 67:109-16. doi: 10.1016/j.jpsychores.2009.05.001

27. Wang R, Chen F, Chen Z, Li T, Harari G, Tignor S, et al. (editors). StudentLife: assessing mental health, academic performance and behavioral trends of college students using smartphones. In: Proceedings of the 2014 ACM International Joint Conference on Pervasive and Ubiquitous Computing. ACM (2014).p. 3-14. doi: 10.1145/2632048.2632054

28. Abdullah S, Matthews M, Murnane EL, Gay G, Choudhury T (editors). Towards circadian computing: early to bed and early to rise makes some of us unhealthy and sleep deprived. In: Proceedings of the 2014 ACM International Joint Conference on Pervasive and Ubiquitous Computing. ACM (2014).

29. Iasonos A, Schrag D, Raj GV, Panageas KS. How to build and interpret a nomogram for cancer prognosis. J Clin Oncol. (2008) 26:136470. doi: 10.1200/JCO.2007.12.9791

30. Zlotnik A, Abraira V. A general-purpose nomogram generator for predictive logistic regression models. The Stata J. (2015) 15:537-46. doi: 10.1177/1536867X1501500212

31. Kawakami S, Numao N, Okubo Y, Koga F, Yamamoto S, Saito K, et al. Development, validation, and head-to-head comparison of logistic regression-based nomograms and artificial neural network models predicting prostate cancer on initial extended biopsy. Eur Urol. (2008) 54:60111. doi: 10.1016/j.eururo.2008.01.017

32. Liang $\mathrm{W}, \mathrm{Xu} \mathrm{L}$, Yang P, Zhang L, Wan D, Huang Q, et al. Novel nomogram for preoperative prediction of early recurrence prediction in intrahepatic cholangiocarcinoma. Front Oncol. (2018) 8:360. doi: 10.3389/fonc.2018.00360

33. Nunnally JC. Psychometric Theory. 2nd ed. Mcgraw Hill Book Company (1978). p. 265.

34. Mun S, Park J, Dritschilo A, Collins S, Suy S, Choi I, et al. The Prostate Clinical Outlook (PCO) classifier application for predicting biochemical recurrences in patients treated by Stereotactic Body Radiation Therapy (SBRT). Appl Sci. (2018) 8:1620. doi: 10.3390/app8091620

35. Kattan MW, Wheeler TM, Scardino PT. Postoperative nomogram for disease recurrence after radical prostatectomy for prostate cancer. J Clini Oncol. (1999) 17:1499-507. doi: 10.1200/JCO.1999.17.5.1499

36. Chun FKH, Karakiewicz PI, Briganti A, Walz J, Kattan MW, Huland H, et al. A critical appraisal of logistic regression-based nomograms, artificial neural networks, classification and regression-tree models, look-up tables and risk-group stratification models for prostate cancer. BJU Int. (2007) 99:794-800. doi: 10.1111/j.1464-410X.2006.06694.x

37. Cocoradă E, Maican CI, Cazan A-M, Maican MA. Assessing the smartphone addiction risk and its associations with personality traits among adolescents. Child Youth Serv Rev. (2018) 93:345-54. doi: 10.1016/j.childyouth.2018.08.006

38. Economist T. Planet of the phones. J Economist. (2015). Available online at: https://www.economist.com/leaders/2015/02/26/planet-of-the-phones

39. Tateno M, Teo AR, Ukai W, Kanazawa J, Katsuki R, Kubo H, et al. Internet addiction, smartphone addiction, and Hikikomori trait in Japanese young adult: social isolation and social network. Front Psychiatry. (2019) 10:455. doi: 10.3389/fpsyt.2019.00455

40. Jeong S-H, Kim H, Yum J-Y, Hwang Y. What type of content are smartphone users addicted to?: SNS vs. games. Comput Hum Behav. (2016) 54:107. doi: $10.1016 /$ j.chb.2015.07.035 
41. Li S-M, Chung T-M. Internet function and Internet addictive behavior. Comput Hum Behav. (2006) 22:1067-71. doi: 10.1016/j.chb.2004.03.030

42. Lee H, Kim JW, Choi TY. Risk factors for smartphone addiction in Korean adolescents: smartphone use patterns. J Korean Med Sci. (2017) 32:16749. doi: 10.3346/jkms.2017.32.10.1674

43. Limayenm M, Hirt SG, Cheung CMK. Habit in the context of is continuance: theory extension and scale development. In: ECIS 2003 Proceedings. 90 (2003). Available online at: http://aisel.aisnet.org/ecis2003/90

44. Chen Z, Lin M, Chen F, Lane ND, Cardone G, Wang R, et al. (editors). Unobtrusive sleep monitoring using smartphones. Proceedings of the 7th International Conference on Pervasive Computing Technologies for Healthcare. ICST (Institute for Computer Sciences, SocialInformatics and Telecommunications Engineering) (2013). p. 44. doi: 10.4108 /icst.pervasivehealth.2013.252148

45. Mohr DC, Zhang M, Schueller SM. Personal sensing: understanding mental health using ubiquitous sensors and machine learning. Ann Rev Clin Psychol. (2017) 13:23-47. doi: 10.1146/annurev-clinpsy-032816-044949

46. Paek K-S. Relationship of sleep quality with smartphone addiction and stress among collegians. Indian J Public Health Res Dev. (2018) 9:70713. doi: $10.5958 / 0976-5506.2018 .00371 .6$

47. Choi $\mathrm{N}$. The correlation of the factors affecting the smartphone addiction of young adult women. Int Informat Ins Informat. (2017) 20:3315-23.

48. Gezgin DM. Relationship among smartphone addiction, age, lack of sleep, fear of missing out and social networking sites use among high school students. Cypriot J Educ Sci. (2018) 13:409-21. doi: 10.18844/cjes.v13i2.2938

49. Xie X, Dong Y, Wang J. Sleep quality as a mediator of problematic smartphone use and clinical health symptoms. J Behav Addic. (2018) 7:46672. doi: $10.1556 / 2006.7 .2018 .40$

50. Ma J-H, Yuan Y-J, Lin S-H, Pan J-YJ. Nomogram for predicting diabetes mellitus after the first attack of acute pancreatitis. Eur J Gastroen Hepat. (2019) 31:323. doi: 10.1097/MEG.0000000000001307
51. Kim Y, Park T. Develop Nomogram to Predict Malignancy of Intraductal Papillary Mucinous Neoplasm. In: Pancreatic Cancer. New York, NY: Humana Press (2019). p. 23-32. doi: 10.1007/978-1-4939-8879-2_3

52. Pivetta E, Harkin L, Billieux J, Kanjo E, Kuss DJ. Problematic smartphone use: an empirically validated model. Comput Hum Behav. (2019) 100:10517. doi: 10.1016/j.chb.2019.06.013

53. Kaur S, Sukhija J, Khanna R, Takkar A, Singh M. Diplopia after excessive smart phone usage. Neuro-Ophthalmol. (2019) 43:323-6. doi: 10.1080/01658107.2018.1518988

54. Kim Y, Jeong J-E, Cho H, Jung D-J, Kwak M, Rho MJ, et al. Personality factors predicting smartphone addiction predisposition: behavioral inhibition and activation systems, impulsivity, and self-control. PLoSone. (2016) 11:e0159788. doi: 10.1371/journal.pone.0159788

55. Choi J, Rho MJ, Kim Y, Yook IH, Yu H, Kim D-J, et al. Smartphone dependence classification using tensor factorization. PLoSone. (2017) 12:112. doi: 10.1371/journal.pone.0177629

56. Buysse DJ, Reynolds CF, Monk TH, Berman SR, Kupfer DJ. The pittsburgh sleep quality index: a new instrument for psychiatric practice and research. Psychiatry Res. (1989) 28:193-213. doi: 10.1016/0165-1781(89)90047-4

Conflict of Interest: The authors declare that the research was conducted in the absence of any commercial or financial relationships that could be construed as a potential conflict of interest.

Copyright () 2020 Park, Jeong, Park and Rho. This is an open-access article distributed under the terms of the Creative Commons Attribution License (CC BY). The use, distribution or reproduction in other forums is permitted, provided the original author(s) and the copyright owner(s) are credited and that the original publication in this journal is cited, in accordance with accepted academic practice. No use, distribution or reproduction is permitted which does not comply with these terms. 